iRASD Journal of Management
Volume 3, Number 2, 2021, Pages $171-184$
JRAS
https://iournals.internationalrasd.org/index.php/iom

\title{
Self-Efficacy as A Function of Work Engagement with The Mediating Role of Organizational Trust in Higher Educational Institutions
}

\author{
Muhammad Adnan ${ }^{1}$, Ather Ummad Khan ${ }^{2}$, Raisham Hayee ${ }^{3}$ \\ ${ }^{1}$ Azteca University, Mexico (UA) \& Universidad Central de Nicaragua (UCN), Republic of Nicaragua (North \\ America), Email: dr.adnanmalik1989@gmail.com \\ 2 National College of Business Administration \& Economics, Lahore Multan Sub-Campus, Pakistan \\ ${ }^{3}$ National College of Business Administration \& Economics, Lahore Multan Sub-Campus, Pakistan
}

\section{ARTICLE INFO}

\section{Article History:}

Received:

Revised:

Accepted:

August 09, 2021

Keywords:

Self-Efficacy

Work Engagement

Organizational Trust

Educationists

Higher Educational Institutions

Southern Punjab

\section{ABSTRACT}

The purpose of this paper is to find out the impact of the selfefficacy on work engagement in the employees working in the organization especially on the educationists (teachers and professors) working in the educational institutions of Southern Punjab, Pakistan. The paper focuses on the survey with a questionnaire containing 30 questions with 7-point Likert Scale ranging from 1.0 (Strongly Disagree) to 7.0 (Strongly Agree) inculcating all three variables (self-efficacy, organizational trust and work engagement). The sample population was obtained from the Southern Punjab including the teachers and professors working in the public as well as private sector institutions. Quantitative data was analyzed through Pearson Correlation and Multiple Linear Regression. The study finds the institutions pertaining to the higher education especially in South Punjab, Pakistan must focus on imparting self-efficacy within the employees to have high performance and growth. The study was based on a single research approach for investigation i.e., quantitative which may affect the investigation's outcomes. Furthermore, the findings of current study are cross-sectional. Future study may entail longitudinal study for investigating the relationship between self-efficacy and work engagement. Moreover, the study has been conducted with one mediator - organizational trust. Future research may go with more or other mediators like working conditions, employees' motivations, goal progress. This study discusses the importance of the self-efficacy in the employees in order to enhance the work engagement within them through building the organizational trust. This study is fist of its kind that discusses the relationship between self-efficacy as well as the work engagement with a mediating role of organizational trust. The paper highlights the importance of the self-efficacy while employees exert their efforts to achieve their objectives enthusiastically due to the trust they have in the organizations.

(C) 2021 The Authors, Published by iRASD. This is an Open Access article under the Creative Common Attribution Non-Commercial 4.0

Corresponding Author's Email: dr.adnanmalik1989@gmail.com

\section{Introduction}

\subsection{Background of the Study}

Work engagement is considered as motivator imparting commitment and performance enhancement not only in the employees but also in the companies. The individuals prefer to work in those organizations where they find themselves more engaged in decision making (Jayachandran, Edwin, \& Vipin, 2021). This leads to enhance the self- 
efficacy in the employees through giving them the trust and confidence for considering organizations as their own.

\subsection{Statement of Research}

Higher education institutions working in South Punjab, Pakistan are struggling multiple pedagogical and non-pedagogical practices in an attempt to enhance the effectiveness of their teaching faculty to compete with the standards globally. According to Jayachandran et al. (2021), in an attempt to motivate the employees for yielding higher level of commitment, competitiveness in market as well as performance of the organization. The employee engagement has put a dramatic impact on the organizational performance (Noshad, Amjad, Shafiq, \& Gillani, 2019). Moreover, according to Musenze, Mayende, Kalenzi, and Namono (2021), employee engagement is a degree to measure the positive as well as negative attachment of the employee towards their role, colleagues as well as organization itself in an attempt to enhance their learning and performance within organization.

Moreover, in social cognitive theory, Bandura (1982) highlighted self-efficacy as a measuring instrument for the person by himself through multiple sources which provide information to the person. These judgments enable the employees to cater their choice patterns as well as responding to multiple environmental issues (Chen, Bao, \& Gao, 2021; Demir, 2020; Liu, 2019; Musenze et al., 2021). The employees with higher self-efficacy have been found to have higher level of commitment, engagement as well as potential towards their organizational roles within which they are working (Chan, Ho, Ip, \& Wong, 2020). Furthermore, the people who are working in any profession require higher level of self-confidence leading to enhance their skills and proficiencies which is only be achieved through higher motivation level. This level of motivation arises in them due to the trust and level of confidence which organization has provided them during their job activities (Aygün, 2021). The purpose of this research study is to investigate the impact of self-efficacy within educationists on their work engagement through mediating effect of organizational trust.

\subsection{Significance of the Study}

Companies should design such policies for providing enriched working environment to their employees through offering effective training programs, efficient resources as well as effective appraisals to improve their self-efficacy, perception regarding working environment as well as their intention for remaining organizational members.

\section{Literature Review \\ 2.1. Work Engagement}

Ortiz-Gómez, Ariza-Montes, and Molina-Sánchez (2020) illustrate that the continuous affective, emotional as well as positive state of workers' behaviors on the job is referred to work engagement. In their study, it is illustrated that the basic ingredients of work engagement are dedication, vigor and absorption. Dedication is the collection of multiple emotional states of a worker like inspiration, challenge, pride, involvement as well as enthusiasm. On the other hand, vigor is devotion of the workers to their work inculcating the energy, effort, challenge as well as pleasure.

Jayachandran et al. (2021) illustrate that work engagement is a good source of motivating the employees to yield higher commitment, performance as well as making the organizations competitive within the market. Moreover, the employees are found to prefer such organizations in which employees are found to be more engaged and involved within business decisions (Jayachandran et al., 2021).

Work engagement has been a function of satisfaction as well as commitment to the work or job assignments (Güzide, 2021). Another study conducted by (Ishiyama, 2021) illustrates that work engagement is a mean to reduce the employee turnover, employee absenteeism and to attract the new talents towards the organizational setting. Dwiparaniti and Netra (2021) exhibit the work engagement within two different school of thoughts: the first school postulates the work engagement as a positive, welfare-related, and work accomplishment state of mind of the employees whereas the other school of thought posits 
the work engagement as a state of mind which is positive in nature but is constructed with commitment, enthusiasm and absorption (Dwiyanti, Na'imah, \& Hamzah, 2021; Güzide, 2021). Dwiparaniti and Netra (2021) highlight that the work engagement is a source of good governance in any company directed by the management in an attempt to create organizational commitment within employees.

The individuals with high engagement scroll the new opportunities, develop new horizons for utilizing their skills and capabilities in order to shape the organizational environment in the new dimension (Chen et al., 2021). The high engaged employees are found coping with complex tasks within dynamic and proactive environments and engage themselves in achieving their objectives (Chen et al., 2021; Dwiparaniti \& Netra, 2021). With suppressing the pleasant emotions, the level of job satisfaction decreases (Castellano, Muñoz Navarro, Toledo, Spontón, \& Medrano, 2019). According to Ferraro, dos Santos, Moreira, and Pais (2020), the employees may achieve the state of work engagement in the absence of job stress and pressure due to repetitive, boring as well as monotonous jobs and enjoys in performing the challenging as well as enthusiastic tasks through balancing the enriched and exciting functions appropriately.

People join the organization for compensation and incentives but they find themselves engaged at work due to the meaningfulness of job as well as activities they perform. When employees find themselves engaged in their job, they find themselves enthusiastic and dedicated about it (Ferraro et al., 2020). The engaged employees find themselves energetic through satisfying the demands of their jobs with an effective connection with the tasks and activities they perform (Dwiyanti et al., 2021).

\subsection{Relationship between Self-Efficacy and Work Engagement}

According to Bandura (1982), self-efficacy is the ability of a person through which one performs his tasks and this is correlated with the performance of organization, role of a person in the organization, the stress of job and responsibility and burnout. This approach is highly conceivable for the managers to play its dominant role in the management decision making.

Bandura (1986) perceives the self-efficacy as a judgement of the person by himself which has been achieved through various efficacy information providing sources. Perceived self-efficacy is dependent upon the appraisal of the person done by himself which is based on the expectancy and anticipation that a person considers to happen (Bandura, 1986). Chen et al. (2021) defined self-efficacy as the judgment of the employees about their own skills in order to perform their job-related assignments which enhance their cognition as well as confidence. The study illustrates that the employees with high self-efficacy are found to be more motivated to exert their fullest extent of capacity, energy as well as they devote more time to accomplish their work responsibilities relative to their jobs. On the other hand, the employees with lower level of self-efficacy find themselves in a situation with high stress and reduce their energy and motivation while performing complex activities (Chen et al., 2021).

Moreover, these judgments cater the choice behavior, self-determination like selfaiding and self-hindering on the mental and cognitive patterns of a human being and enable the person to respond to the environmental issues (Ahmad, Bashir, \& Hussain, 2018; Liu, 2019). As every individual has different kinds of skills, capabilities, cognitions and attitudes, the organizations have to inculcate such environment that this high workforce diversity may easily be encountered in their structure (Jayachandran et al., 2021). The study illustrates that the employees must have their skills such that they can easily cope them up in such diverse cultural norms of the organization and enhance their performance under such diversified environment (Amjad, Ehsan, Amjad, \& Gillani, 2021; Jayachandran et al., 2021). Güzide (2021) in their research study highlight that self-efficacy is a sign of difference among cognitive, imaginative and attitudinal norms of the people working in any organizational setting. 
This illustrates that the higher level of self-efficacy leads to increase the self-esteem, self-assurance and consequently, self-confidence while one is exerting his capabilities and efforts in an attempt to achieve the goals and increases the level of commitment and motivation in the person during his job (Liu, 2019). Furthermore, this self-efficacy is highly instigated through the transformational leadership which becomes a strong source for clarifying the goals to other organizational members through communicating them with high level of self-confidence (Salanova, Rodríguez-Sánchez, \& Nielsen, 2020). Further, selfefficacy determines the preferences of the individuals while making any decision which develops the organizational trust in the individual through increasing the motivation level which reduces the effects of obstacles and hinderances while achieving the organizational goals (Chen et al., 2021; Demir, 2020). The above discussion reveals that due to increase in the self-efficacy of the person, there is higher tendency to increase the engagement of the workers in their jobs and work responsibilities. The following hypothesis statements reveals out from this discussion:

H1: There is a positive relationship between self-efficacy and work engagement of the educationists of Southern Punjab HEIs.

\subsection{Relationship between the Self-Efficacy and Organizational Trust}

According to Chen et al. (2021), the employees find themselves more attached to the company if they find some problem or issue during their work responsibilities and the other members provide them the solutions as well as keep these issues to them in order to keep the fellow secure. This illustrates the emergence of a new behavioral element organizational trust - which has been developed within the employees when they find other members with a positive and favorable attitude within difficult and complex situations while performing their work responsibilities. On the other hand, this provides them a new dimension to sharp their skills and efficiencies within the organizational domain. This postulates another hypothesis statement of this study:

H2: There exists a positive relationship between the self-efficacy and the organizational trust.

\subsection{Organizational Trust}

Organizational Trust is a self-motivating process and is coined through the relationship between leader and followers (Ilyas, Abid, \& Ashfaq, 2020). An emotional state of a person about the organization that it may facilitate him/her in every domain. Aygün (2021) illustrates that organizational trust is basically a mutual relationship between employees and employers and if there is no trust exists in the organization, it develops suspiciousness and anxiety among both the parties (employees as well as employers) whenever any change arises within organization. In an attempt to create healthy, productive as well as effective working environment in any organizational setting, there must be a sense of trust as well as effective communication within it (Aygün, 2021; Shair et al., 2021; Zhuang et al., 2021). The people working any business or organization, there must be high self-confidence within employees as it leads to enhance the performance skills and capabilities of employees due to higher level of motivation (Bhatti, Farhan, Ahmad, \& Sharif, 2019). This motivation arises due to the trust and confidence provided by the organization to its members during performing their job activities (Aygün, 2021). This component implies that one party trusts the other due to both are following the same codes of conduct and contain a trustworthy experience in the past (Ilyas et al., 2020). According to (Tekingündüz, Karabel, Zekioğlu, \& Sünbül, 2020), an organizational member believes to receive cooperation and support at the time of need in order to solve the problem with no conditions provides him/her a feeling of trust, confidence and commitment.

The continuous interaction among the organizational members within the organization as well as outside organizational boundaries becomes a strong source of developing positive or negative feelings of employees towards the company within which they are working (Aygün, 2021). Moreover, Srivastava and Madan (2020) argue that organizational trust is a determinant of employees' openness and honesty and is triggered through the personal and group rapport as well as integrity. With the same node, Jarrar and Ibrahim (2021), in their research study, illustrate that trust is an emotional and 
psychological state which is out of any fear as well as hesitation and neither side of relationship entails exploitation especially in the sense of perceived weakness of some party and consequently, results in the positive actions from every individual.

On the other side, Quttainah (2019) categorizes the organizational trust as the ability of the trustors containing no power while confronting the activities performed by the trustee and illustrates trustees as retail organization whereas trustors have been treated as the customers (Fu \& Jiao, 2019). For instance, there are high chances for reciprocity of the employees' attitude towards their work and job when they have trust in the organization (Amine, 2020). Furthermore, trust is considered as a core element for the success, growth and development of the organization on the long-term basis due to the risks and rivalry in existing business environment throughout the globe (Chen et al., 2021). Yilmaz and Toylan (2021), in their study, illustrate three sub-dimensions of the organizational trust: trust in the employee, trust in the organization as well as interpersonal trust.

They claim organizational trust is a desire of organizational members in an attempt to perform their responsibilities justly, honestly, committedly and relevantly within the relationships and interactions among organizational members with complete awareness regarding their objectives, goals, missions and values. In their study, they postulate that there is an interconnectivity between employees as well as organizations which entails the organizational trust and within this trustworthiness, they achieve their and organizational objectives effectively (Yilmaz \& Toylan, 2021). Through this above literature, it is evident that the organizational trust leads the employees to engage within the job and work. This postulates another hypothesis for this study described below:

H3: There exists a positive relationship between the organizational trust and work engagement of employees within the organization.

On the basis of these postulated hypotheses statements which have been illustrated above, a theoretical framework has been defined which illustrates these hypotheses statements in a diagram. This theoretical framework defines the relationships between the variables defined in the study i.e., Self-efficacy, organizational trust and work engagement. Following is the theoretical framework which has been set for the current study defined under the literature review:

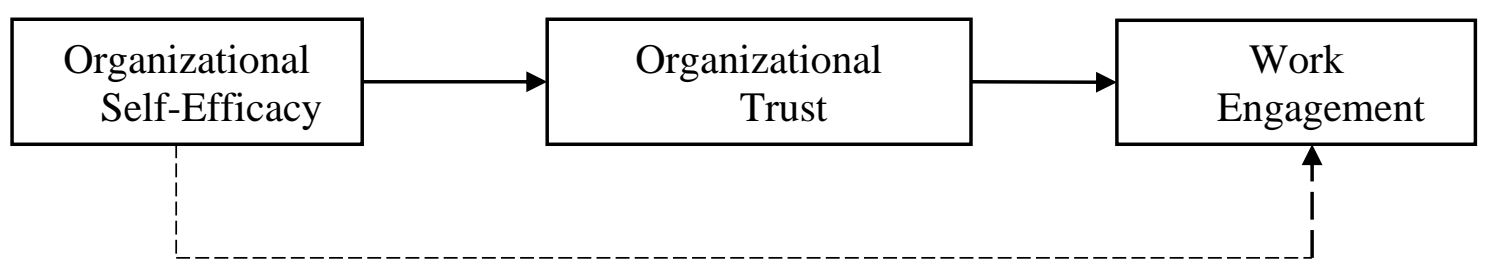

Figure 1: ETC Framework

\section{Methodology \\ 3.1. Research Design}

In this section, the primary decision is to decide the approach used to conduct the research study within quantitative, qualitative or mixed method (M. Saunders, Lewis, \& Thornhill, 2019). This current study undergoes with quantitative method using questionnaire Positivism is the philosophy using the reality-based information and is found to be consistent with each other (D. H. Saunders et al., 2020). Moreover, the study undergoes with deductive research approach considering research questions, hypotheses statements and research findings as it is found to be the best fit with observed phenomena derived from hypotheses statements.

\subsection{Population}

The population for the current study is the educationists or teachers teaching in the higher education institutions in South Punjab, Pakistan. The rationale for selecting this 
population is to create awareness in the minds of the institutions to build self-efficacy within the employees so as they could be highly engaged not only with the system but also with their own careers.

\subsection{Sample}

The sample size for the current study is 200 comprising from the institutions in South Punjab, Pakistan providing higher education to the students.

\subsubsection{Sampling Technique}

The technique for sampling used in this study is convenience sampling. The rationale behind using this technique is that the data may be collected easily and conveniently from educationists of South Punjab.

\subsection{Theory Underpinning: \\ 3.4.1.Self-Efficacy Theory}

Self-Efficacy theory states that self-efficacy is the psychological state of individuals in which they believe in their skills for performing their activities (of job as well as life events) at the best and find a sense of motivation, milestone achievement as well as their well-being (Bandura, 1986). The current study also highlights the same phenomenon when individuals find themselves high in their self-efficacy, they feel themselves more committed and motivated towards their job roles.

\subsection{Data Collection}

The researchers used multiple institutions in South Punjab, Pakistan in an attempt to collect the data which constitute the population of the study. The questionnaires were dispersed among educationists who are used to engage in the teaching process at any level in the institution. The questionnaires were filled up from 200 educationists to conduct the survey. Gender disproportion for the respondents is notable as $68 \%$ of the participants were male whereas the female participation was $32 \%$ of the total sample.

\subsection{Research Instrument and Scale Measures 3.6.1.Self-Efficacy}

In an attempt to measure the self-efficacy of the teachers in the higher education, the study adapted the scale which already had been used in a research investigation conducted by Peterson (2020). The scale designed in 7.0-point Likert Scale anchoring with 1: Strongly Disagree, 2: Partially Disagree, 3: Disagree, 4: Neutral, 5: Agree, 6: Partially Agree, 7: Strongly Agree.

\subsubsection{Organizational Trust}

While attempting to measure organizational trust provided to the educationists in higher education, the present study adapted the scale already used in research study conducted by Hasan (2021) anchored with following scale: 1: Strongly Disagree, 2: Partially Disagree, 3: Disagree, 4: Neutral, 5: Agree, 6: Partially Agree, 7: Strongly Agree.

\subsubsection{Work Engagement}

To assess the work engagement established in the educationists in higher education, the current study adapted the scale used earlier in the research investigation conducted by Wang and Chen (2020) with 7.0-point Likert Scale anchoring with: 1: Strongly Disagree, 2: Partially Disagree, 3: Disagree, 4: Neutral, 5: Agree, 6: Partially Agree, 7: Strongly Agree.

\subsection{Data Analysis}

The current study used Variance-based Partial Least Square-Structural Equation Modelling (PLS-SEM), very common in management disciplines to generalize as well as 
integrate the latent variables' constructs with principal component and regression analysis. Work engagement is a formative construct and target construct of structural model in the current study supported theoretically. According to (Joe F Hair, Sarstedt, Ringle, \& Mena, 2012), the most suitable approach is PLS-SEM for such constructs. The study undergoes with structural modelling (investigating the relationships between the latent variables) as well as assessing the measurement model (evaluating the validity and reliability of latent constructs).

\section{Results}

\subsection{Descriptive Statistics and Correlational Analysis}

Sample mean (M), standard deviations (STDEV), T-statistics and their corresponding P-values have been shown in Table 1 illustrating the significance of the relationships among the latent variables.

\section{Table 1}

Descriptive Statistics

\begin{tabular}{lccc}
\hline & $\begin{array}{c}\text { Original Sample } \\
(\mathbf{O})\end{array}$ & $\begin{array}{c}\text { Sample Mean (M) } \\
\text { OT -> WE }\end{array}$ & $\begin{array}{c}\text { Standard Deviation } \\
\text { (STDEV) }\end{array}$ \\
\hline SE -> OT & 0.624 & 0.632 & 0.066 \\
SE -> WE & 0.295 & 0.304 & 0.062 \\
\hline
\end{tabular}

Inter-construct correlation showing the correlation of latent variables with other latent variables have been illustrated in Table 2 whereas Table 3 exhibits the correlations between the indicators of the latent variables.

Table 2

Inter Construct Correlation

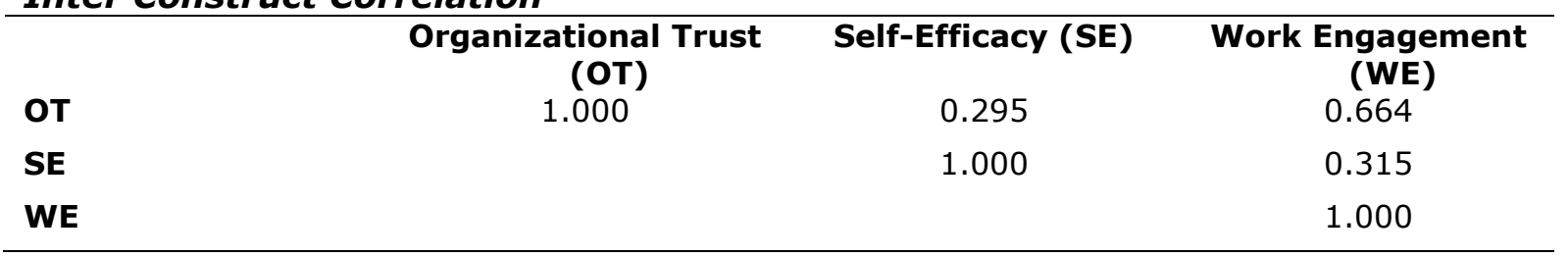

Table 3

Indicators' Correlation

泉

$\stackrel{\circ}{\mathrm{N}}$

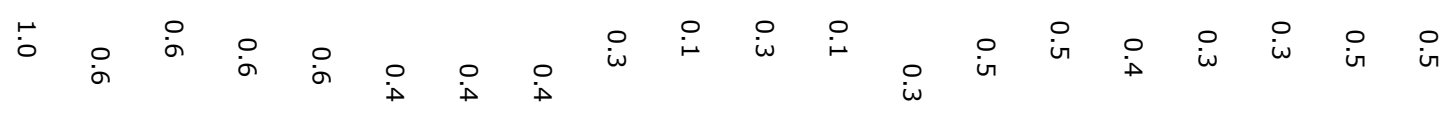

$\underset{\mathrm{O}}{\stackrel{9}{\omega}}$

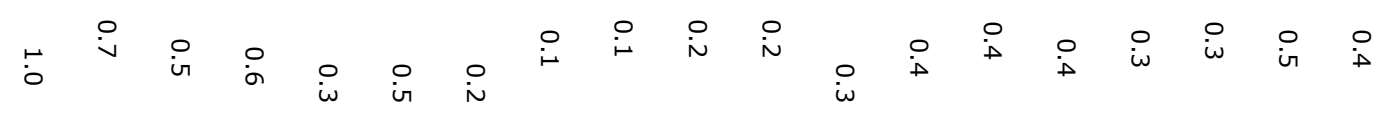

$\stackrel{9}{+}$

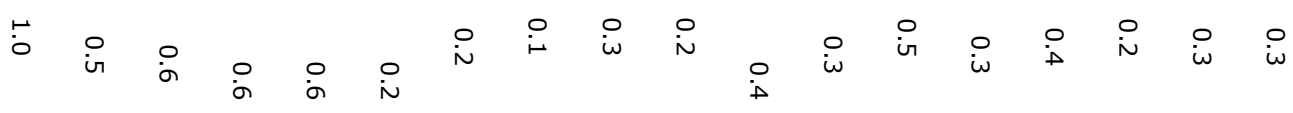

곤

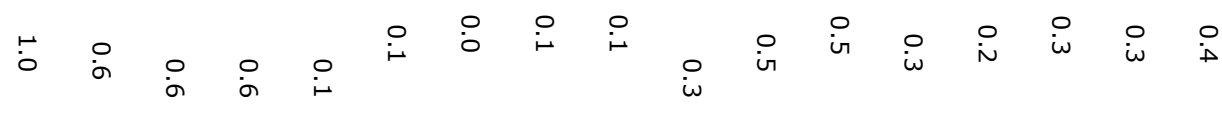


iRASD Journal of Management 3(2), 2021

옹

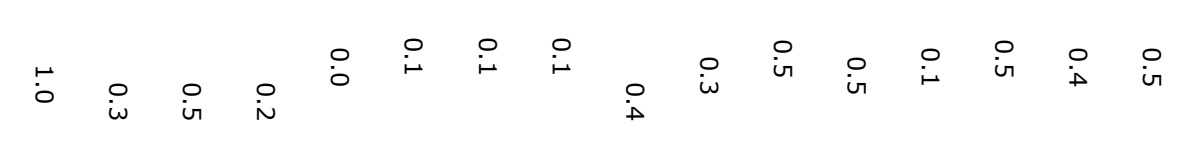



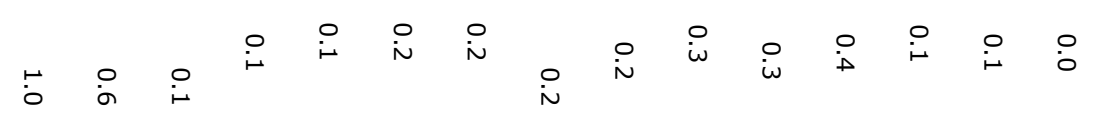

옹

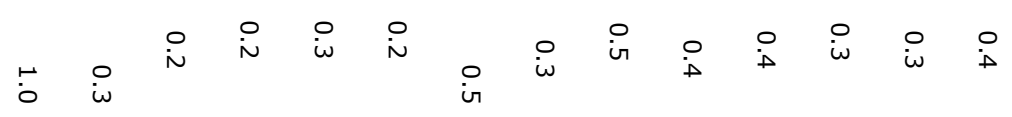

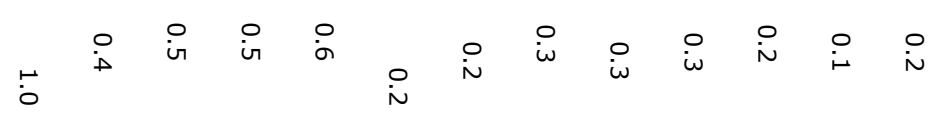

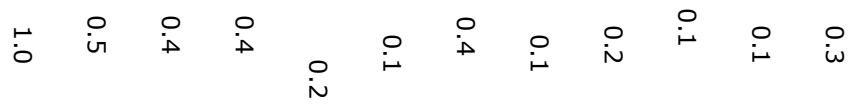

嵒

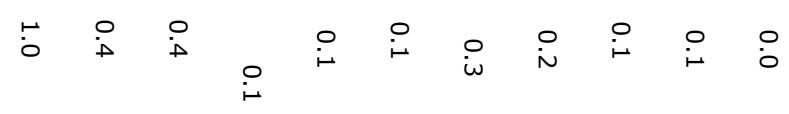

骨

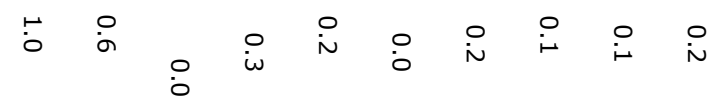

通

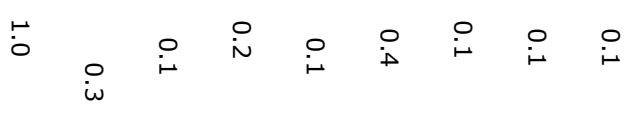

$\underset{\mathrm{m}}{\sum}$

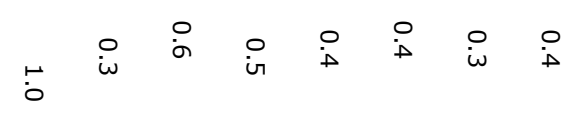

$+\stackrel{\circ}{\circ}$ in $i$ i

$\underset{\mathrm{N}}{\xi}$

$$
\overrightarrow{0} \text { in } \stackrel{\circ}{i} \text { in } i
$$

涌

$$
+\stackrel{i}{i} \text { in } \stackrel{i}{i}
$$

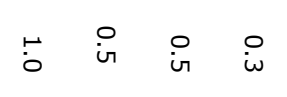

192 
$\sum_{\mathrm{M}}^{\mathrm{m}}$

$\underset{\infty}{\mathbf{m}}$

苗

\subsection{Mediation Analysis}

The results indicated by the tables $1,2 \& 3$ illustrate that self-efficacy, organizational trust and work engagement have been statistically found significant. The results highlight a positive relationship between self-efficacy (SE) and organizational trust (OT) $(r=0.304$, $p<0.01)$ as well as work engagement (WE) $(r=0.134, p<0.01)$. Furthermore, there was found a strong, positive and significant relationship between organizational trust (OT) and work engagement (WE) $(r=0.632, p<0.01)$. On these findings, Hypotheses statements 1 \& 2 were supported. Furthermore, Table 4 illustrates the mediation effect of organizational trust (OT) within the relationship between self-efficacy (SE) and work engagement (WE) indicating a significant, positive and strong mediating effect of OT in between SE and WE $(r=0.192, p<0.01)$.

Table 4

Specific Indirect Effect

\begin{tabular}{lccccc}
\hline & $\begin{array}{c}\text { Original } \\
\text { Sample } \\
(\mathbf{O})\end{array}$ & $\begin{array}{c}\text { Sample Mean } \\
(\mathbf{M})\end{array}$ & $\begin{array}{c}\text { Standard } \\
\text { Deviation } \\
\text { (STDEV) }\end{array}$ & $\begin{array}{c}\text { T Statistics } \\
(\mathbf{O} / \mathbf{S T D E} \\
\mathbf{V} \mid)\end{array}$ & P Values \\
\hline SE $->$ OT $->$ WE & 0.184 & 0.192 & 0.043 & 4.292 & 0.000 \\
\hline
\end{tabular}

\subsection{Measurement Model}

To measure internal consistency in exploratory research, the satisfactory values of Cronbach's Alpha and composite reliability should be between 0.6 and 0.7 whereas the values between 0.7 as well as 0.9 illustrate satisfactory result for good reliability (Joseph $F$ Hair, Risher, Sarstedt, \& Ringle, 2019). The results of the current study for measuring the construct reliability and validity have been illustrated in Table 5.

Table 5: Construct Reliability and Validity

\begin{tabular}{lcccc}
\hline Variables & Cronbach's Alpha & rho_A & $\begin{array}{c}\text { Composite } \\
\text { Reliability }\end{array}$ & $\begin{array}{c}\text { Average Variance } \\
\text { Extracted } \\
\text { (AVE) }\end{array}$ \\
\hline OT & 0.893 & 0.898 & 0.913 & 0.541 \\
SE & 0.815 & 0.851 & 0.86 & 0.512 \\
WE & 0.877 & 0.881 & 0.9 & 0.502 \\
\hline
\end{tabular}

According to Sarstedt, Ringle, and Hair (2017), while measuring the convergent validity, the value of indicator loading should be greater than 0.70 and the value for average variance extracted (AVE) and indicator reliability should be larger than 0.50 . The values of outer loadings for each construct for the current study has been illustrated through Table 6.

Moreover, to determine discriminant validity, Fornell-Larcker criterion and crossloadings are used. Based on Fornell-Larcker criterion, the value of correlation with other latent variables should be lower than the square root of average variance extracted (AVE) for each latent variable. Additionally, the outer loading for an indicator of a construct should 
have a value larger than the cross loading with all other variables (Sarstedt et al., 2017). The results for discriminant validity under Fornell-Larcker criterion has been exhibited in Table 7.

Table 6

Outer Loading

\begin{tabular}{lccc}
\hline & Organizational Trust & Self-Efficacy & $\begin{array}{c}\text { Work } \\
\text { Engagement }\end{array}$ \\
\hline OT2 & 0.804 & & \\
OT3 & 0.8 & & \\
OT4 & 0.828 & & \\
OT5 & 0.803 & & \\
OT6 & 0.78 & & \\
OT7 & 0.746 & 0.814 & \\
OT8 & 0.757 & 0.889 & \\
SE10 & & 0.875 & \\
SE2 & & 0.777 & \\
SE3 & & 0.794 & 0.792 \\
SE8 & & & 0.701 \\
SE9 & & & 0.802 \\
WE1 & & 0.744 \\
WE10 & & 0.87 \\
WE2 & & 0.76 \\
WE3 & & 0.71 \\
WE4 & & & 0.799 \\
WE5 & & & \\
WE8 & & & \\
WE9 & & & \\
\hline
\end{tabular}

Table 7

Discriminant Validity

\begin{tabular}{lccc}
\hline & Organizational Trust (OT) & Self-Efficacy (SE) & Work Engagement (WE) \\
\hline OT & 0.776 & & \\
\hline SE & 0.295 & 0.752 & \\
WE & 0.664 & 0.315 & 0.711 \\
\hline
\end{tabular}

The results indicate that items have satisfactory level for both convergent validity as well as reliability with significant outer loading $(>0.70)$, acceptable AVE $(>0.50)$, good indicator reliability $(>0.50$ ) as well as higher level of internal consistency for each of the three latent variables (self-efficacy, organizational trust and work engagement) having the values of Cronbach's alpha and composite reliability in between 0.877 and 0913 . As the scale met the criteria of evaluating the discriminant validity based on Fornell-Larcker criterion as well as higher outer loading, it has been found that all three latent variables discriminated each other clearly.

\subsection{Structural Model}

After assessing the measuring models, in smart PLS, next step is to evaluate the validity of structural model. In an attempt to measure the validity of the structural model, coefficient of determination $\left(R^{2}\right)$ reflects the integrated effect of exogeneous latent constructs on a target endogenous latent construct with the acceptable range of values between 0 and 1 (Joseph $F$ Hair et al., 2019) and the higher values exhibit the higher explanatory power of the research framework or model. As illustrated in Table 8 , the value of $\mathrm{R}^{2}$ for organizational trust (OT) (0.087) and work engagement (0.456) showing positive and moderate but weak value (Joseph F Hair et al., 2019).

Table 8

R Square

\begin{tabular}{ccc}
\hline & R Square & R Square Adjusted \\
\hline OT & 0.087 & 0.083 \\
WE & 0.456 & 0.451 \\
\hline
\end{tabular}


In an attempt to assess the change in the $R^{2}$ value, the value of $f^{2}$ is to be considered for an endogenous latent construct (Sarstedt et al., 2017). Table 9 highlights the size of impact of organizational trust (OT) on work engagement was found strong and significant i.e., 0.654 whereas the impact of self-efficacy on organizational trust (OT) and work engagement (WE) was found low i.e., 0.096 and 0.03 respectively.

\section{Table 9}

F Square

\begin{tabular}{cccc}
\hline & $\begin{array}{c}\text { Organizational } \\
\text { Trust (OT) }\end{array}$ & $\begin{array}{c}\text { Self-Efficacy (SE) } \\
\text { Work Engagement } \\
\text { (WE) }\end{array}$ \\
\hline OT & & 0.654 \\
\hline SE & 0.096 & 0.03 \\
\hline WE & & \\
\hline
\end{tabular}

In an attempt to evaluate the path coefficients' significance, a bootstrap procedure was run for establishing the CIs (confidence intervals) for the coefficients of the latent constructs. This bootstrap procedure doesn't require normality assumption for sampling distribution. According to Joseph F Hair et al. (2019), a significant path coefficient lies if zero doesn't fall in lower as well as upper $95 \%$ CIs. Table 10 illustrates that no zero falls in the lower and upper $95 \%$ CIs for the current study.

Table 10

Confidence Intervals

\begin{tabular}{lcccc}
\hline & Original Sample (0) & Sample Mean (M) & $\mathbf{2 . 5 0 \%}$ & $\mathbf{9 7 . 5 0 \%}$ \\
\hline OT -> WE & 0.624 & 0.632 & 0.505 & 0.757 \\
SE -> OT & 0.295 & 0.304 & 0.189 & 0.427 \\
SE -> WE & 0.133 & 0.134 & 0.018 & 0.245 \\
\hline
\end{tabular}

Moreover, for a two-tailed test, a critical $t$-value greater than 1.96 at $p<0.05$ indicates the significance of path coefficient (Joseph $\mathrm{F}$ Hair et al., 2019). Table 11 illustrates that the $t$-value is greater than 1.96 with corresponding $p$-value is less than 0.05 indicating the significance of path coefficients of the model in the current study.

Table 11

Path Coefficients

\begin{tabular}{lccccc}
\hline & $\begin{array}{c}\text { Original } \\
\text { Sample } \\
(\mathbf{O})\end{array}$ & $\begin{array}{c}\text { Sample } \\
\text { Mean } \\
(\mathbf{M})\end{array}$ & $\begin{array}{c}\text { Standard } \\
\text { Deviation } \\
(\text { STDEV) }\end{array}$ & $\begin{array}{c}\text { T Statistics } \\
(\mathbf{I O} / \mathbf{S T D E} \\
\mathbf{V} \mid)\end{array}$ & P Values \\
\hline OT -> WE & 0.624 & 0.632 & 0.066 & 9.425 & 0.000 \\
SE -> OT & 0.295 & 0.304 & 0.062 & 4.798 & 0.000 \\
SE -> WE & 0.133 & 0.134 & 0.061 & 2.189 & 0.002 \\
\hline
\end{tabular}

Table 4 \& Table 11 illustrate the direct and indirect effects, exhibiting the impact of self-efficacy on work engagement with mediator (organizational trust). The results highlight that the indirect effect of independent construct (self-efficacy), through the mediator (organizational trust), on work engagement was found to be significant $(r=0.192, p<$ 0.05). This result supports the hypotheses 3. The strength of the mediation of organizational trust was calculated by using Variance Accounted For (VAF) which is determined by dividing the indirect effect by the sum of indirect as well as direct effect (i.e., total effect) which had the value of 0.589 , indicating that $58.9 \%$ effect of the self-efficacy was explained on work engagement through organizational trust. The mediation found with this result had been classified as partial mediation as the value of VAF has fallen between $20 \%$ and $80 \%$ (Sarstedt et al., 2017). With this notion, it is evident that organizational trust was serving as a complementary mediator in this study. 


\subsection{Discussion}

The current research study investigated the relationships within self-efficacy, organizational trust and work engagement in a sample of higher education educationists in South Punjab, Pakistan. The researchers focused to investigate whether the self-efficacy of these educationists contributes to their work engagement through organizational trust. The findings of the study supported the hypotheses statements of the study.

In this study, the educationists with higher level of self-efficacy were found to be more satisfied with the trust and confidence provided to them by the organization as well as more engaged with their work responsibilities. Furthermore, the findings of this study are found to be in line with the previous research investigations in the domain of self-efficacy and work engagement (Aygün, 2021; Baloran \& Hernan, 2020; Chan et al., 2020), exhibiting self-efficacy as a major contributor to engage the workers towards their job responsibilities through the trust and confidence provided to them by the organizations. Particularly, organizational trust has been found to mediate partially the relationship between self-efficacy as well as work engagement.

Furthermore, the results of this study support to Bandura's self-efficacy theory illustrating the value of having a belief in the skills and competencies of one's self as well as intrinsic motivation to be engaged within the role and responsibilities assigned to them by the organizations. Along with this, the study also supports the theoretical background provided by the previous literature (Bogler \& Nir, 2012; Musenze et al., 2021; Zheng, Wang, Doll, Deng, \& Williams, 2018) that the employees have higher level of belief in themselves if organization provides a strong trust to them during their job responsibilities.

\section{Conclusions}

The primary findings of the study indicate the emergence of self-efficacy in educationists in the higher education institutions in South Punjab, Pakistan. There is a need to devise such strategic decisions not only to apprehend the educationists' skills but also to support their skills enhancement through their trust and confidence building in the organization. Enhanced self-efficacy attributes to enhance the confidence among educationists leads to moral, ethical and behavioral development of the students with such confidence building (Javed, Nawaz, \& Qurat-Ul-Ain, 2015; Musenze et al., 2021).

Moreover, there are multiple other tasks have been assigned to educationists reducing their performance and self-efficacy. This practice must be avoided. Moreover, institutions must provide professional trainings to educationists to meet the need of modern era. To enhance self-efficacy in educationists' skills to cater complex professional assignments, there is a need to engage teachers in skill development programs and handson professional experiences.

\subsection{Limitations}

Undoubtedly, there have been found multiple inevitable stands for the previous literature regarding self-efficacy as well as work engagement but some limitations have been found. Firstly, there is only one mediator in current study - organizational trust. There would be some other potential variables which may be accounted for in an attempt to investigate the mediation between self-efficacy and work engagement i.e., working conditions, employees' motivation, goal progress (Chan et al., 2020; Musenze et al., 2021). Secondly, this research study is cross-sectional. Thirdly, the study entails the self-reported data collection instruments which consequently, results in data biasness. Finally, the present research study has been conducted in a domain of South Punjab, Pakistan which is not so well urbanized area of Pakistan.

\subsection{Future Research Directions}

There are multiple elements which future research studies may incorporate to enhance this research study like multiple mediators can be used. The future studies may undergo with longitudinal time horizons. Moreover, future research may extend this study through using multiple sources of data and apprehend this study to some other area. 


\section{References}

Ahmad, R., Bashir, F., \& Hussain, A. (2018). Human capital, governance and poverty reduction: A panel data analysis. Review of Economics and Development Studies, 4(1), 103-113. doi:https://doi.org/10.26710/reads.v4i1.285

Amine, M. E. A. (2020). Ethical Climate and Organizational Citizenship Behaviors: the Mediating Role of Organizational trust. European Journal Of Business And Management, 12(3), 33-41.

Amjad, A., Ehsan, S., Amjad, M., \& Gillani, S. (2021). Impact of Shareholders' Activism on Governance Practices and Firm Performance in Pakistan: A Response for Family Controlled Firms. iRASD Journal of Economics, 3(1), 1-12. doi:https://doi.org/10.52131/joe.2021.0301.0021

Aygün, M. (2021). Analysis of the Relationship between Job Satisfaction and Organizational Trust of Physical Education and Sports Teachers. Journal of Pedagogical Research, 5(1), 203-215. doi:https://doi.org/10.33902/jpr.2021167583

Baloran, E., \& Hernan, J. (2020). Crisis Self-Efficacy and Work Commitment of Education Workers among Public Schools during COVID-19 Pandemic. Preprints. doi:10.20944/preprints202007.0599.v1

Bandura, A. (1982). Self-efficacy mechanism in human agency. American psychologist, 37(2), 122. doi:https://doi.org/10.1037/0003-066X.37.2.122

Bandura, A. (1986). The explanatory and predictive scope of self-efficacy theory. Journal of social and clinical psychology, 4(3), 359-373. doi:https://doi.org/10.1521/jscp.1986.4.3.359

Bhatti, M. A., Farhan, M., Ahmad, M. J., \& Sharif, M. N. (2019). The Impact of Social CRM Capabilities and Customer Engagement on the Firm Performance: Mediating Role of Social Media Usage. Pakistan Journal of Humanities and Social Sciences, 7(3), 313-324. doi:https://doi.org/10.52131/pjhss.2019.0703.0089

Bogler, R., \& Nir, A. E. (2012). The importance of teachers' perceived organizational support to job satisfaction: What's empowerment got to do with it? Journal of educational administration, 50(3), 287-306. doi:https://doi.org/10.1108/09578231211223310

Castellano, E., Muñoz Navarro, R., Toledo, M. S., Spontón, C., \& Medrano, L. A. (2019). Cognitive processes of emotional regulation, burnout and work engagement. Psicothema, 31(1), 73-80. doi:https://doi.org/10.7334/psicothema2018.228

Chan, E. S., Ho, S. K., Ip, F. F., \& Wong, M. W. (2020). Self-efficacy, work engagement, and job satisfaction among teaching assistants in hong kong's inclusive education. SAGE Open, 10(3), 2158244020941008. doi:https://doi.org/10.1177/2158244020941008

Chen, P., Bao, C., \& Gao, Q. (2021). Proactive Personality and Academic Engagement: The Mediating Effects of Teacher-Student Relationships and Academic Self-Efficacy. Frontiers in Psychology, 12, 1824. doi:https://doi.org/10.3389/fpsyg.2021.652994

Demir, S. (2020). The role of self-efficacy in job satisfaction, organizational commitment, motivation and job involvement. Eurasian Journal of Educational Research, 20(85), 205-224.

Dwiparaniti, N. K., \& Netra, I. G. S. K. (2021). The Effect of Transformational Leadership on Organizational Commitment Mediated by Work Engagement. American Journal of Humanities and Social Sciences Research (AJHSSR), 5(6), 140-144.

Dwiyanti, R., Na'imah, T., \& Hamzah, H. B. (2021). WORK ENGAGEMENT: THE ROLE OF AFFECTIVE WELLBEING AND SUPERVISOR SUPPORT. International Journal of Management (IJM), 12(4), 266-274. doi:https://doi.org/10.34218/IJM.12.4.2021.023

Ferraro, T., dos Santos, N. R., Moreira, J. M., \& Pais, L. (2020). Decent work, work motivation, work engagement and burnout in physicians. International Journal of Applied Positive Psychology, 5(1-2), 13-35. doi:https://doi.org/10.1007/s41042-019-00024-5

Fu, J., \& Jiao, H. (2019). Study on The Effect Mechanism of Vision Leadership on Employee Performance: the Mediating Role of Trust Tendency and the Regulating Role of Self-Efficacy. Paper presented at the 7th International Education, Economics, Social Science, Arts, Sports and Management Engineering Conference (IEESASM 2019).

Güzide, A. (2021). Study on Factors Affecting Accountants Job Stress: Focusing On Self-Efficacy, Job Satisfaction and Work Engagement. Revista Argentina de Clínica Psicológica, 30(1), 587-595.

Hair, J. F., Risher, J. J., Sarstedt, M., \& Ringle, C. M. (2019). When to use and how to report the results of PLS-SEM. European business review, 3(1), 1-24. 
Hair, J. F., Sarstedt, M., Ringle, C. M., \& Mena, J. A. (2012). An assessment of the use of partial least squares structural equation modeling in marketing research. Journal of the academy of marketing science, 40(3), 414-433. doi:https://doi.org/10.1007/s11747-011-0261-6

Hasan, K. K. (2021). The relationship between intellectual capital and organizational trust and its impact on achieving the requirements of entrepreneurship strategy (The case of Korek Telecom Company, Iraq). International Journal of Multicultural and Multireligious Understanding, 8(2), 130-146. doi:http://dx.doi.org/10.18415/ijmmu.v8i2.2405

llyas, S., Abid, G., \& Ashfaq, F. (2020). Ethical leadership in sustainable organizations: The moderating role of general self-efficacy and the mediating role of organizational trust. Sustainable Production and Consumption, 22, 195-204. doi:https://doi.org/10.1016/j.spc.2020.03.003

Ishiyama, N. (2021). The impact of the talent management mechanism and self-perceived talent status on work engagement: the case of Japan. Asia Pacific Business Review, 1-19. doi:https://doi.org/10.1080/13602381.2021.1905410

Jarrar, T. T., \& Ibrahim, H. I. (2021). The Role of Perceived Stress as a Moderator on the Relationship between Organizational Trust and Work Engagement in Palestinian Ministries: An Empirical Approach. International Journal Of Human Resource Studies, 11(2). doi:https://doi.org/10.5296/ijhrs.v11i2.18286

Javed, M., Nawaz, M. A., \& Qurat-Ul-Ain, A. (2015). Assessing Postgraduate Students' Critical Thinking Ability. Journal on Educational Psychology, 9(2), 19-26.

Jayachandran, N., Edwin, A., \& Vipin, H. (2021). Employee Engagement-The Key to Teaching Self Efficacy. Asian Journal of Economics, Finance and Management, 4(2), 26-30.

Liu, E. (2019). Occupational self-efficacy, organizational commitment, and work engagement. Social Behavior and Personality: an international journal, 47(8), 1-7. doi:https://doi.org/10.2224/sbp.8046

Musenze, I. A., Mayende, T. S., Kalenzi, A., \& Namono, R. (2021). Perceived organizational support, selfefficacy and work engagement: testing for the interaction effects. Journal of Economic and Administrative Sciences. doi:https://doi.org/10.1108/JEAS-08-2020-0141

Noshad, M., Amjad, M., Shafiq, M. N., \& Gillani, S. (2019). Performance and Obstacles of SMEs: An Empirical Evidence from BRICS Countries. iRASD Journal of Economics, 1(2), 113-131. doi:https://doi.org/10.52131/joe.2019.0101.0010

Ortiz-Gómez, M., Ariza-Montes, A., \& Molina-Sánchez, H. (2020). Human values and work engagement: the mediating role of authenticity among workers in a spanish religious organization. Frontiers in Psychology, 11, 76. doi:https://doi.org/10.3389/fpsyg.2020.00076

Peterson, R. A. (2020). Self-efficacy and personal selling: review and examination with an emphasis on sales performance. Journal of Personal Selling \& Sales Management, 40(1), 57-71. doi:https://doi.org/10.1080/08853134.2019.1654390

Quttainah, M. A. (2019). The Role of Organizational Trust and JOY in Organization's Strategic Behaviour. FIIB Business Review, 9(1), 42-54. doi:https://doi.org/10.1177/2319714519872855

Salanova, M., Rodríguez-Sánchez, A. M., \& Nielsen, K. (2020). The impact of group efficacy beliefs and transformational leadership on followers' self-efficacy: A multilevel-longitudinal study. Current Psychology, 1-10. doi:https://doi.org/10.1007/s12144-020-00722-3

Sarstedt, M., Ringle, C. M., \& Hair, J. F. (2017). Partial least squares structural equation modeling. Handbook of market research, 26(1), 1-40.

Saunders, D. H., Sanderson, M., Hayes, S., Johnson, L., Kramer, S., Carter, D. D., . . Mead, G. E. (2020). Physical fitness training for stroke patients. Cochrane Database of systematic reviews(3). doi:https://doi.org/10.1002/14651858.CD003316.pub7

Saunders, M., Lewis, P., \& Thornhill, A. (2019). Research methods for business students. In: Pearson.

Shair, F., Shaorong, S., Kamran, H. W., Hussain, M. S., Nawaz, M. A., \& Nguyen, V. C. (2021). Assessing the efficiency and total factor productivity growth of the banking industry: do environmental concerns matters? Environmental Science and Pollution Research, 28(16), 20822-20838. doi:https://doi.org/10.1007/s11356-020-11938-y

Srivastava, S., \& Madan, P. (2020). The relationship between resilience and career satisfaction: Trust, political skills and organizational identification as moderators. Australian Journal of Career Development, 29(1), 44-53. doi:https://doi.org/10.1177/1038416219886317 
Tekingündüz, S., Karabel, E., Zekioğlu, A., \& Sünbül, S. Ö. (2020). Modeling the Relationship Between Organizational Trust, Job Performance, Identity and Organizational Identification. Işsletme Araştırmaları Dergisi, 12(2), 1192-1206.

Wang, C.-H., \& Chen, H.-T. (2020). Relationships among workplace incivility, work engagement and job performance. Journal of Hospitality and Tourism Insights, 3(4), 415-429. doi:https://doi.org/10.1108/JHTI-09-2019-0105

Yilmaz, N., \& Toylan, N. V. (2021). The Relationships Between Psychological Empowerment Organizational Trust and Employee Motivation: An Empirical Research on Hotel Employees in Istanbul. Journal of Tourism and Gastronomy Studies, 9(1), 111-130. doi:https://doi.org/10.21325/jotags.2021.780

Zheng, Y., Wang, J., Doll, W., Deng, X., \& Williams, M. (2018). The impact of organisational support, technical support, and self-efficacy on faculty perceived benefits of using learning management system. Behaviour \& Information Technology, 37(4), 311-319. doi:https://doi.org/10.1080/0144929X.2018.1436590

Zhuang, Y., Yang, S., Chupradit, S., Nawaz, M. A., Xiong, R., \& Koksal, C. (2021). A nexus between macroeconomic dynamics and trade openness: moderating role of institutional quality. Business Process Management Journal, 27(6), 1703-1719. doi:https://doi.org/10.1108/BPMJ-12-2020$\underline{0594}$ 